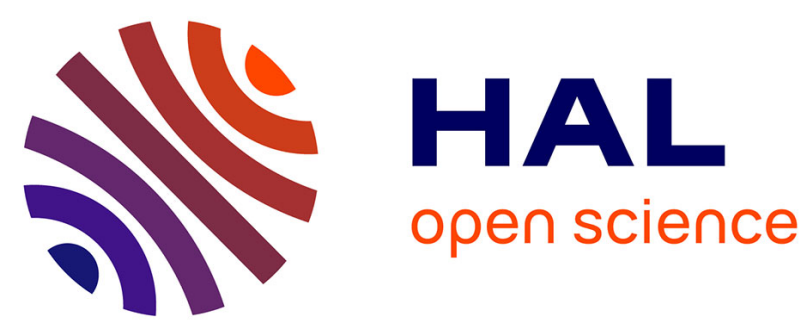

\title{
Effect of point mutations on the ultrafast photo-isomerization of Anabaena sensory rhodopsin
}

D. Agathangelou, Y. Orozco-Gonzalez, M. del Carmen Marín, Pascal Roy, J. Brazard, H. Kandori, K. H. Jung, J. Léonard, T. Buckup, Nicolas Ferré, et al.

\section{- To cite this version:}

D. Agathangelou, Y. Orozco-Gonzalez, M. del Carmen Marín, Pascal Roy, J. Brazard, et al.. Effect of point mutations on the ultrafast photo-isomerization of Anabaena sensory rhodopsin. Faraday Discussions, 2018, 207, pp.55-75. 10.1039/x0xx00000x . hal-02053159

\section{HAL Id: hal-02053159 \\ https://hal-amu.archives-ouvertes.fr/hal-02053159}

Submitted on 1 Mar 2019

HAL is a multi-disciplinary open access archive for the deposit and dissemination of scientific research documents, whether they are published or not. The documents may come from teaching and research institutions in France or abroad, or from public or private research centers.
L'archive ouverte pluridisciplinaire HAL, est destinée au dépôt et à la diffusion de documents scientifiques de niveau recherche, publiés ou non, émanant des établissements d'enseignement et de recherche français ou étrangers, des laboratoires publics ou privés.

\section{(c)(1)}

Distributed under a Creative Commons Attribution| 4.0 International License 


\section{Journal Name}

\section{ARTICLE}

\section{Effect of point mutations on the ultrafast photo-isomerization of Anabaena Sensory Rhodopsin}

Received 00th January 20xx, Accepted 00th January $20 x x$ DOI: $10.1039 / x 0 \times x 00000 x$

www.rsc.org/

D. Agathangelou ${ }^{a}$, Y. Orozco-Gonzalez ${ }^{\mathrm{a}, \mathrm{g}}$, M. del Carmen Marín ${ }^{\mathrm{b}}$, P. P. Roy ${ }^{\mathrm{c}}$, J. Brazard ${ }^{\mathrm{a}}$, H. Kandori ${ }^{\mathrm{d}}$, K.-H. Jung ${ }^{e}$, J. Léonard ${ }^{a}$, T. Buckup ${ }^{c}$, N. Ferré ${ }^{f}$, M.Olivucci ${ }^{b, g, h}$, and S.Haacke ${ }^{a,+}$

Anabaena Sensory Rhodopsin is a particular microbial retinal protein for which light-adaptation leads to the ability to bind both the all-trans, 15-anti (AT) and the 13-cis, 15-syn (13C) isomers of the protonated Schiff base of retinal (PSBR). In the context of obtaining insight into the mechanisms by which retinal proteins catalyse the PSBR photo-isomerization reaction, ASR is a model system allowing to study, within the same protein, the protein -PSBR interactions for two different PSBR conformers at the same time. A detailed analysis of the vibrational spectra of AT and $13 \mathrm{C}$, and their photo-products in wildtype ASR obtained through femtosecond (pump-) four-wave-mixing is reported for the first time, and compared to bacterioand channelrhodopsin. As part of an extensive study of ASR mutants with blue-shifted absorption spectra, we present here a detailed computational analysis of the origin of the mutation-induced blue-shift of the absorption spetra, and identify electrostatic interactions as dominating steric effects that would entail a red-shift. The excited state lifetimes and isomerization reaction times (IRT) for the three mutants $\mathrm{V} 112 \mathrm{~N}, \mathrm{~W} 76 \mathrm{~F}$, and $\mathrm{L} 83 \mathrm{Q}$ are studied experimentally by femtosecond broadband transient absorption spectroscopy. Interestingly, in all three mutants, isomerization is accelerated for AT with respect to wild-type ASR, and this the more, the shorter the wavelength of maximum absorption. On the contrary, the $13 \mathrm{C}$ photo-reaction is slightly slowed down, leading to an inversion of the ESLS of AT and 13C, with respect to wt-ASR, in the blue-most absorbing mutant L83Q. Possible mechanisms for these mutation effects, and their steric and electrostatic origins are discussed.

\section{Introduction}

Light-induced processes in retinal proteins (RPs) have attracted vivid attention over the past two decades from experimentalists and theoreticians alike ${ }^{1-7}$. While initial work revealed the time scales for isomerization of the PSBR, and how they depend on the protein species or on point mutations, more attention was recently devoted to the mechanism, by which the protein steers this ultrafast reaction. New femtosecond spectroscopic ${ }^{8-19}$ and quantum chemistry tools were devised ${ }^{20-26}$ with the aim of drawing a very detailed picture of the excited state multidimensional potential energy surface (PES) including the conical

\footnotetext{
a. University of Strasbourg, CNRS, Inst. de Physique et Chimie des Matériaux de Strasbourg, 67034 Strasbourg, France.

${ }^{b .}$ Department of Biotechnology, Chemistry and Pharmacy, University of Siena, via A. Moro 2, I-53100 Siena, Italy.

c. Physikalisch-Chemisches Institut, Ruprecht-Karls Universität Heidelberg, 69120 Heidelberg, Germany.

d. Department of Frontier Materials, Nagoya Institute of Technology, Showa-ku, Nagoya 466-8555, Japan

${ }^{e}$. Department of Life Science and Institute of Biological Interfaces, Sogang University, Shinsu-Dong 1, Mapo-Gu, Seoul 121-742, South Korea

f. Aix-Marseille University, CNRS, ICR, Marseille, France

${ }^{g}$. Department of Chemistry, Bowling Green State University, Bowling Green, Ohio 43403, United States

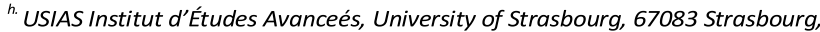
France

+ Corresponding author: haacke@unistra.fr.

Electronic Supplementary Information (ESI) available: [details of any supplementary information available should be included here]. See DOI: 10.1039/x0xx00000x
}

intersection $(\mathrm{Cl})$ seam, of the time-resolved motion of PSBR at the atomic level, the reaction-driving vibrational modes and the dynamic changes in the charge distribution on PSBR and in the protein electrostatics. Additional, though partial, insight on these aspects comes from comparative studies of PSBR in solution ${ }^{27-34}$ and of proteins reconstituted with non-isomerizing PSBR derivatives ${ }^{35-37}$.

While the relatively high complexity of the system impairs the ability to single out specific molecular or structural factors, it is generally accepted that the protein globally acts by limiting the isomerization to one specific double bond of the PSBR backbone and to increase the reaction quantum yield by steric and electrostatic constraints, preventing ultrafast non-productive routes ${ }^{38}$ or possibly modifying the conical intersection (Cl) topology 22,3940 .

Nevertheless, the process by which the protein environment tunes the excited state PES or $\mathrm{Cl}$ so as to shorten the $\mathrm{S}_{1}$ lifetime and accelerates the reaction remains an open question. The recently discovered Anabaena Sensory Rhodopsin (ASR) offers a very interesting test ground in that context. ${ }^{7,41-44}$ It bears a mixture of all-trans,15-anti (AT) and 13-cis, 15-syn (13C) PSBR isomers, the relative content of which depends on the illumination, so-called 'light-adaptation' conditions. When left in the dark, the dark-adapted (DA) form adopts $97 \%$ AT, which drops to less than $40 \%$ under illumination with orange light, at neutral $\mathrm{pH}^{4245}$ ASR therefore allows to study the PSBR protein 
interactions for two PSBR conformations, but with the same environment.

In this context, the observation of strikingly different excited state lifetimes (ESL) for AT ( $0.7 \mathrm{ps}^{46,47}$ ), and $13 \mathrm{C}$ (approx. $150 \mathrm{fs}$ ${ }^{44,47}$ ) may be related to the different PSBR conformations ${ }^{48}$, but also to different electrostatic or dynamic interactions with the protein charge distribution. These findings were in qualitative agreement with quantum chemistry computations of the excited state potential energy surface (PES) along the minimum energy paths in ASR ${ }^{43}$, and with excited state trajectory calculations ${ }^{7}$. There, it was found that the $S_{1}$ PES of $13 \mathrm{C}$ is barrierless, while that of the AT form displays a plateau or a slight barrier that could account for a short resting period of the excited state population. Importantly, both reaction paths lead to a conical intersection seam with the ground state PES. The precise origin of these different shapes of the $S_{1}$ PES for both isomers remains unclear, however. As we reported recently ${ }^{48}$, a precise analysis of the nanosecond isomer difference spectra confirmed that AT has a 2.7-times higher reaction quantum yield (QY) than 13C, and that ASR has the lowest QY ever reported for RPs $(<0.2)$. The former result is intuitively surprising, a shorter ESL would imply a larger $Q Y^{49}$, but is related to the fact that both quantities are fundamentally independent since determined by separate, independent regions of the PES. While the ESL reports about population decay close to the Franck-Condon region, the $Q Y$ is a matter of transition probabilities and wave packet trajectories around the $\mathrm{Cl}^{47}$. Here, we report on ultra-broadband probed TA and transient Raman experiments performed with $<30 \mathrm{fs}$, respectively $20 \mathrm{fs}$ time resolution. The latter reports new and precise data for the $\mathrm{C}=\mathrm{C}, \mathrm{C}-\mathrm{C}$ stretch and methyl rocking frequencies for $\mathrm{AT}, 13 \mathrm{C}$ ground states and their primary photoproducts $K_{A T}$ and $K_{13 C}$. As an extension of previous reports on ASR wild-type, we are focussing here on the effect of point mutations on the ESL of AT and $13 \mathrm{C}$ isomers. The mutants investigated $-\mathrm{V} 112 \mathrm{~N}, \mathrm{~L} 83 \mathrm{Q}$ and W76F - were chosen due to their high level of expression in $\mathrm{E}$. Coli and the relatively large blue shifts their DA and LA ground state spectra afford, indicating significant changes of the electrostatic protein-PSBR interactions with respect to wild-

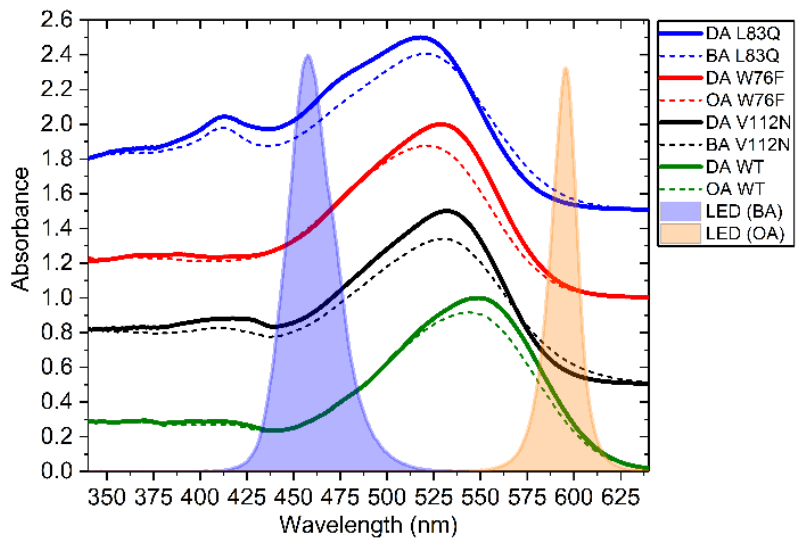

Figure 1: Normalized ground state absorption spectra of light- and dark-adapted wtASR and the three mutants V112N, W76F and L83Q. Spectra are vertically shifted by multiples of 0.5 units. The spectral intensity distributions of the OA and BA LED's used for light-adaptation are displayed in orange and blue, respectively. type. Interestingly, for AT, the blue shifts are correlated with a reduction of the ESL, attaining $120 \mathrm{fs}$ for the blue-most shifted mutant L83Q. On the contrary, the ESL of $13 \mathrm{C}$ is barely affected or at most increased by a factor of two via mutations, as compared to wt-ASR.

\section{Materials and methods}

ASR mutants were expressed in E. Coli, prepared according to reported protocol ${ }^{24,31}$ and solubilized in buffer $(150 \mathrm{mM} \mathrm{NaCl}$, $50 \mathrm{mM}$ Tris-HCL, $0.02 \% \mathrm{DDM}, \mathrm{pH}$ 7.0). Steady state absorption spectra of dark-adapted (DA) and light-adapted (LA) protein samples were obtained using a Perkin Elmer "Lambda 950" UV/VIS spectrometer equipped with integrating sphere detection. DA samples were prepared by incubation in dark for at least $12 \mathrm{~h}$ at room temperature. LA of the samples was obtained by constant illumination for $30 \mathrm{~min}$ using Luxeon LEDs, LXHL-NB98 $(460 \pm 15 \mathrm{~nm})$, or LXHL-PL01 $(590 \pm 10 \mathrm{~nm})$. The former is referred to blue-adaptation (BA) and the latter to orangeadaptation (OA). The procedure for determining the absorption maxima of all-trans, 15-anti (AT) and 13-cis,15-syn (13C) isomers was already described elsewhere ${ }^{47}$. We measure the absorption spectra of the dark-adapted (DA) and light-adapted (LA) proteins, determine the isomer content in both states after retinal oxime extraction by High Performance Liquid Chromatography (HPLC) ${ }^{50}$, and use the fact that the absorption spectra of DA and LA are linear combinations of AT and $13 \mathrm{C}$ absorbances according to the equations:

$$
\left[\begin{array}{c}
A T \\
13 C
\end{array}\right]=R^{-1} \times\left[\begin{array}{c}
A_{D A} \\
A_{L A}
\end{array}\right] \quad \text { with } \quad R=\left[\begin{array}{cc}
r_{D A}^{A T} & r_{D A}^{13 C} \\
r_{L A}^{A T} & r_{L A}^{13 C}
\end{array}\right] \quad \text { eq. } 1
$$

Transient absorption spectroscopy (TAS) was carried out with an improved time resolution (IRF $40 \pm 5 \mathrm{fs}$ ), using a home-built non-collinear OPA with typically $30 \mathrm{fs}$ pulse width as a pump source. The spectral widths of the pulses were deliberately limited in order to reduce the spectral region of pump light scattering. The pump wavelength was adjusted to be on the low-energy side of the absorption maxima, i.e. $530 \mathrm{~nm}$ for $\mathrm{L} 83 \mathrm{Q}$, $535 \mathrm{~nm}$ for $\mathrm{V} 112 \mathrm{~N}$, and $540 \mathrm{~nm}$ for W76F. The excitation density was kept low enough in order to be in a linear excitation regime. Broadband probing was achieved with white-light pulses (330$1000 \mathrm{~nm}$ ) generated by $40 \mathrm{fs}$ pulses at $800 \mathrm{~nm}$ in a $2-\mathrm{mm} \mathrm{CaF}_{2}$ window. Acquisition of single TAS spectra on a $1 \mathrm{kHz}$ rate, ensured high sensitivity $\left(\Delta \mathrm{A}_{\mathrm{min}} \approx 5 \times 10^{-5}\right)$, which in the present case is rather limited by the scattering properties of the protein samples. Data are averaged from 14 time scans (1400 laser pulses). All data are corrected for signal contributions from the solvent or flow cell and for the white-light group velocity dispersion (20fs accuracy) ${ }^{47}$. All decay traces are fitted by multiexponential functions convolved with the IRF approximated as a Gaussian ${ }^{51}$.

For the transient vibrational spectroscopy, DFWM and PumpDFWM experiments were employed as described in detail in references ${ }^{52-54}$. In short, two home-built non-collinear optical parametric amplifiers $(1 \mathrm{kHz})$ were used to generate ultrashort excitation and probing pulses with typical durations below $15 \mathrm{fs}$. The spectrum of actinic-pump (AP) was made resonant to the 
molecular ground state absorption, while the DFWM spectrum was spectrally overlapped with the photo-induced, ground state photo-product absorption of ASR, respectively (Error! Reference source not found. (a)-(b)). Energy of the AP beam was $100 \mathrm{~nJ}$. DFWM energies were set to $50 \mathrm{~nJ}$ for the pump and Stokes and $10 \mathrm{~nJ}$ for the probe. A rapid scan measurement was realized with a piezo, which continuously scans the delay between Stokes and probe pulses $(\tau)$ (Error! Reference source not found. (c)). The delay between pump and Stokes $\left(\tau_{12}\right)$ was kept zero in all measurements. Vibrational spectra were obtained by Fourier transformation, zero padding and windowing the oscillatory signal after the initial 50fs. The optical density (OD) of the ASR sample was around 0.9 at $545 \mathrm{~nm}$. The sample was circulated through a fused silica flow cell with a path length of about $1 \mathrm{~mm}$ by a motor-driven pump.

\section{Effect of light- and dark-adaptation on steady-state absorption spectra of the mutants: Experiments and computational results}

The ground state absorption spectra of the light-adapted and dark-adapted (DA) forms are reported in Figure 1 for the 3 mutants studied and for wt-ASR as a reference. All DA spectra are normalized to 1.0 , since extinction coefficients were not available, and the LA spectra are plotted with the experimental relative reduction in absorbance. Table 1 summarizes the wavelengths of absorption maxima, the isomer composition, as well as the absorption maxima of the isomer specific spectra (not shown) obtained after linear decomposition ${ }^{47}$. Lightadaptation was carried out either with an orange (OA) or a blue (BA) LED (see Materials and Methods), and the light-adaptation with the highest $13 \mathrm{C}$ isomer ratio was retained. V112N and W76F exhibit a blue-shift under LA as wt-ASR and many other mutants. The absorption spectrum of the $13 \mathrm{C}$ isomer of these mutants shifts by $2 \mathrm{~nm}$ (V112N) and $8 \mathrm{~nm}$ (W76F). L83Q, the blue-most shifted mutant, surprisingly shows the opposite effect, with the $13 \mathrm{C}$ isomer being $6 \mathrm{~nm}$ red-shifted with respect to AT. Finally, we note that mutations induce 18,21 and $33 \mathrm{~nm}$ blue-shifts, i.e. between 615 (76 meV) and $1160 \mathrm{~cm}^{-1}(145 \mathrm{meV})$ spectral shifts.

\begin{tabular}{|lllll|}
\hline Sample & State & AT $\%$ & $13 C \%$ & Abs max $(\mathrm{nm})$ \\
\hline WT & DA & $97 \pm 1$ & $3 \pm 1$ & $550 \pm 1$ \\
& OA & $42 \pm 1$ & $58 \pm 1$ & $543 \pm 1$ \\
& AT & & & $550 \pm 1$ \\
& 13C & & & $537 \pm 1$ \\
\hline V112N & DA & $98 \pm 1$ & $2 \pm 1$ & $532 \pm 1$ \\
& BA & $42 \pm 1$ & $58 \pm 1$ & $530 \pm 1$ \\
& AT & & & $532 \pm 1$ \\
& 13C & & & $527 \pm 1$ \\
\hline W76F & DA & $96 \pm 1$ & $4 \pm 1$ & $529 \pm 1$ \\
& OA & $42 \pm 1$ & $58 \pm 1$ & $521 \pm 1$ \\
& AT & & & $529 \pm 1$ \\
& 13C & & & $514 \pm 1$ \\
\hline L83Q & DA & $98 \pm 1$ & $2 \pm 1$ & $517 \pm 1$ \\
& BA & $44 \pm 1$ & $56 \pm 1$ & $520 \pm 1$ \\
& AT & & & $517 \pm 1$ \\
& 13C & & & $523 \pm 1$ \\
\hline
\end{tabular}

Table 1: Isomer content of wt-ASR and the three mutants in the DA, OA and BA conditions, together with the measured maxima of absorption, highlighting the effect of light-adaptation. The maxima of isomer-specific ground state absorption spectra are calculated according to the linear decomposition method given in Ref. $^{47}$.

We report now the results obtained with $Q M / M M$ models of Anabaena Sensory rhodopsin (ASR) and three of their mutants (V112N, W76F and L83Q) computed by the semi-automatic ARM protocol $^{55}$. ARM employs the multi-configurational complete active space self-consistent field (CASSCF) method to obtain ground state geometries. Excitation energies are then computed using multiconfigurational second-order perturbation theory (CASPT2) to recover the missing dynamical electron correlation associated with the CASSCF description.

The computed values obtained with ARM, are reported in Table S1 (cf. ESI) and plotted in Figure 2, where they are compared to the experimental values determined above. Apart from the previously documented $^{55} \approx 2-3 \mathrm{kcal} / \mathrm{mol}$ overestimation of the computed values, the experimental trend is well reproduced for all mutants except for $\mathrm{L} 83 \mathrm{Q}$, where the ARM model fails to reproduce the

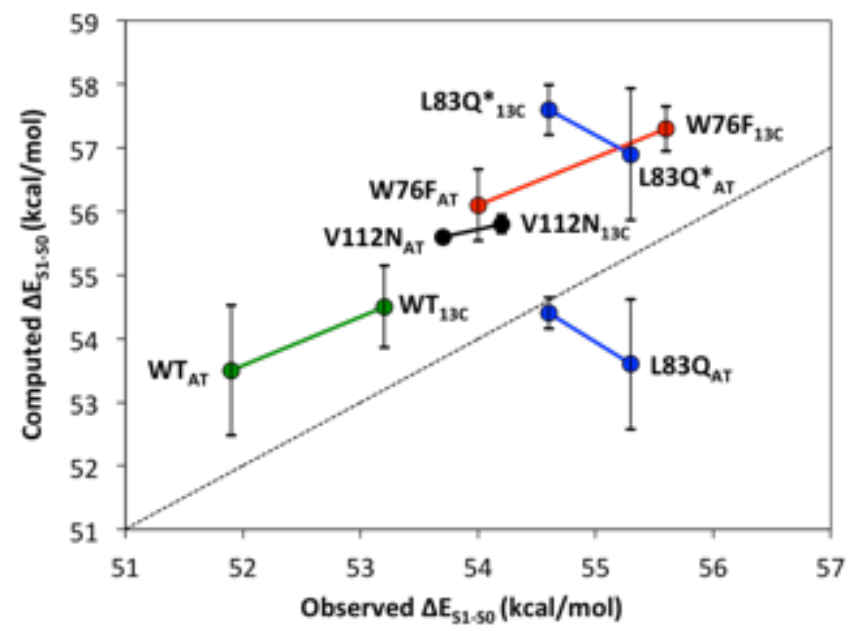

Figure 2: Comparison between computed and observed $\Delta \mathrm{E}_{\mathrm{S1}-\mathrm{so}}(\mathrm{kcal} / \mathrm{mol})$ values from ARM models of ASR WT (green), V112N (black), W76F (red), L83Q and modified L83Q* (blue) mutants. The error bars of the standard deviation are show in black.

observed $\lambda_{\max }$ values, and predicts the opposite trend of LA. Further investigation reveals that the discrepancy with respect to experiments is related to the orientation of the $\mathrm{O}-\mathrm{H}$ dipole moment of the Glu83 residue towards the protonated Schiff base nitrogen (see Fig. S2 in $\mathrm{SI}$ ). The $\mathrm{QM} / \mathrm{MM}$ model generated by the ARM protocol orients this dipole with the positive end facing the SB (Fig. $S 2 A)$, leading to destabilization of the ground state $\left(S_{0}\right)$. However, a second lower energy minimum (see Table S2 in the SI) is found, manually, for an orientation of the $\mathrm{O}-\mathrm{H}$ dipole, with the negative end pointing toward the SB nitrogen (see fig. S2B), thus stabilizing $\mathrm{S}_{0}$, and generating a blue-shift of $\lambda_{\max }$ similar to the experimental value. Nevertheless, while the $283 Q^{*}{ }_{\text {AT }}$ appears to provide a $\lambda_{\max }$ substantially in line with the general trend, $\mathrm{L}^{2} \mathrm{BQ}{ }^{*}{ }_{13 \mathrm{C}}$ is clearly too blue shifted and, thus, the LA effect is not predicted in the right order (see also Table S1). Within a new computational protocol analyzing the total free energy of the protein, we are presently exploring a possible isomer-dependence of the protonation states of other amino acids in the retinal binding pocket, and orientation of Glu83 and Lys. We conclude that LA, in L83Q, causes a structural 
modification that cannot be correctly captured by the present modelling technique. Accordingly, the $L 83 Q$ computational data will not be discussed/analyzed in the following.

We now focus on the differences between the WT model and the $\mathrm{V} 112 \mathrm{~N}$ and $\mathrm{W} 76 \mathrm{~F}$ mutant models. Mutants are usually challenging to model due to the smaller changes in the observed $\Delta \mathrm{E}_{\mathrm{S1} \text {-so }}$ values and the absence of crystallographic data or other structural information. In spite of this difficulty, the computed $\mathrm{WT}, \mathrm{V} 112 \mathrm{~N}$ and $\mathrm{W} 76 \mathrm{~F} \Delta \mathrm{E}_{\mathrm{S1} \text {-so }}$ trend parallels the observed values with only a relatively small blue-shifted deviation in the absolute $\Delta \mathrm{E}_{\mathrm{s1}-\mathrm{so}}$ values. The mutants studied show significant blue-shifts with respect to the WT reference, e.g. the computed $\Delta \mathrm{E}_{\mathrm{S1}-\mathrm{s} 0}$ change between $\mathrm{WT}$ and the most blue-shifted mutant (W76F) is $2.6 \mathrm{kcal} / \mathrm{mol}$ for the AT and 2.8 $\mathrm{kcal} / \mathrm{mol}$ for the $13 \mathrm{C}$ isomer. We have computationally disentangled the electrostatic and steric effects causing the total blue shift by computing the $\Delta \mathrm{E}_{\mathrm{S1} \text {-so }}$ values of the three chromophores in the gas-phase (keeping the chromophore geometries fixed at their optimized protein structure). In fact, the gas-phase $\Delta \mathrm{E}_{\mathrm{S} 1 \text {-so }}$ value reflects the change in chromophore geometry induced by only the steric interaction with the protein cavity. By comparing the electrostatic and steric effects of the different chromophore cavities, we show that the electrostatic effect is the dominant one (Table 2, last column). These effects are due to the different stabilization of the chromophore ground state $\left(S_{0}\right)$ and first excited state $\left(S_{1}\right)$, which are characterized by different electronic distributions (Fig. S1), due the change in the protein charges and positions induced by the mutation. It is well-known that PSBR's photo-excited state $S_{1}$ is characterized by a partial charge transfer (ca. $30 \%)^{56}$ electronic configuration. On the other hand, $\mathrm{S}_{0}$ is dominated by a covalent electronic configuration, with the positive charge localized at the protonated Schiff base. The interaction of both electronic configurations with the mutated PSBR binding cavity explains the observed blue-shifts: For both the V112N and W76F mutants, a change from Valine and Tryptophan to Asparagine and Phenylalanine respectively, near the $\beta$-ionone ring of the chromophore produces a destabilization of the $S_{1}$ rather than a stabilization of $S_{0}$. The observed blue-shift is thus a combined effect of $S_{1}$ up-shift and $S_{0}$ down-shift, but the former is larger in amplitude than the latter, which may be an important information for the mutation effects on the $S_{1}$ kinetics (see Table S3 in the SI).

\begin{tabular}{|c|c|c|c|c|}
\hline Sample & State & $\begin{array}{c}\Delta \mathrm{E}_{\mathrm{S1} \text {-so }} \\
\text { Protein } \\
\text { Environment }\end{array}$ & $\begin{array}{c}\Delta \mathrm{E}_{\mathrm{S1}-\mathrm{So}} \\
\text { Vacuum } \\
\text { (Steric } \\
\text { contribution) }\end{array}$ & $\begin{array}{c}\text { Effect of } \\
\text { mutation: } \\
\text { e.-static } \\
\text { contr. }\end{array}$ \\
\hline \multirow{2}{*}{ WT } & AT & 53.5 & 41.8 & \\
\hline & $13 \mathrm{C}$ & 54.5 & 43.1 & \\
\hline \multirow{2}{*}{ V112N } & AT & 55.6 & $40.2(-1.6)$ & +3.7 \\
\hline & $13 \mathrm{C}$ & 55.8 & $40.9(-2.2)$ & +3.5 \\
\hline \multirow{2}{*}{ W76F } & AT & 56.1 & $36.3(-5.5)$ & +8.1 \\
\hline & $13 \mathrm{C}$ & 57.3 & $39.1(-4.0)$ & +6.8 \\
\hline
\end{tabular}

Table 2: Comparison of the vertical excitation energies $\Delta \mathrm{E}_{\mathrm{s1}-\mathrm{so}}(\mathrm{kcal} / \mathrm{mol})$ computed at CASPT2/CASSCF(12,12)/6-31G*/AMBER level of theory for ASR WT and the mutants $\mathrm{V} 112 \mathrm{~N}$ and $\mathrm{W} 76 \mathrm{~F}$ when the retinal chromophore is inside the protein $\left(\triangle \mathrm{E}_{51-50}\right.$ Protein
Environment) and in vacuum ( $\Delta \mathrm{E}_{\mathrm{s1}-\mathrm{so}}$ Vacuum), supposing the same conformation as in the protein. This allows to separate the dominant electrostatic effect of the mutations from conformational changes.

Notice that, as usually found ${ }^{57}$, the chromophores separated from their protein environments present $\Delta \mathrm{E}_{\mathrm{S1} \text {-so }}$ values about $12-20 \mathrm{kcal} / \mathrm{mol}\left(\Delta \mathrm{E}_{\mathrm{S1}-\mathrm{so}}\right.$ Vacuum $)$ lower than for the chromophore inside the protein ( $\Delta \mathrm{E}_{\mathrm{S} 1 \text {-so }}$ Protein Environment) (Table 2). Interestingly, the mutation-induced changes of the PSBR configurations cause, with respect to the WT a red-shift and not a blue-shift in all $\Delta \mathrm{E}_{\mathrm{S1}-\mathrm{so}}$ values. However, as is shown in Table 2, the electrostatic contribution of the cavity dominates, causing a global blue-shift for the present mutants, with the strongest effect observed for the W76F mutant. In conclusion, the observed blue-shifts of the $\mathrm{V} 112 \mathrm{~N}$ and $\mathrm{W} 76 \mathrm{~F}$ are dominated by the change in the electrostatics of the chromophore hosting cavity. In Fig. S3 we provide a qualitative explanation of the electrostatic effects, which clearly show how the V112N mutation creates a new dipole moment destabilizing $\mathrm{S}_{1}$ with respect to $S_{0}$. In contrast, the $W 76 F$ mutation removes a dipole moment vector, which, in wild-type, stabilizes the $S_{1}$ with respect to $S_{0}$.

\section{Photo-isomerization kinetics of wild-type ASR studied by femtosecond vibrational spectroscopy}

Understanding the ultrafast vibrational evolution is a central aspect in the investigation of the reaction dynamics of the retinal chromophore ${ }^{58-63}$ Time resolved vibrational spectroscopies, like degenerate four wave mixing (DFWM) ${ }^{53,64}$, Pump-degenerate four wave mixing (Pump-DFWM) ${ }^{52,54,65-69}$,

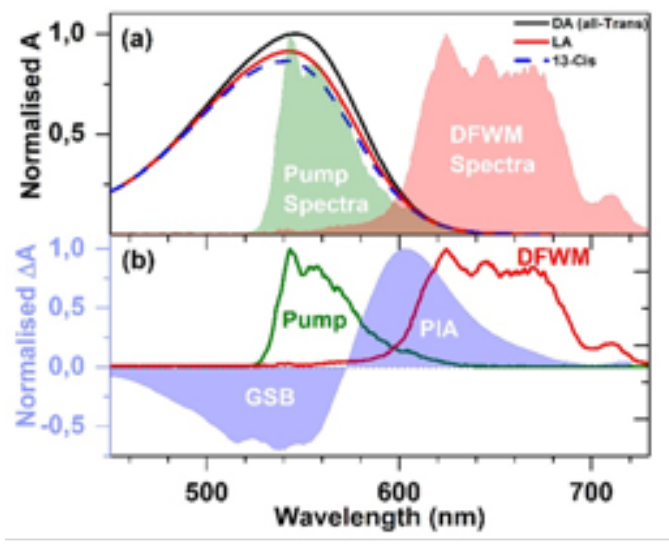

(c)

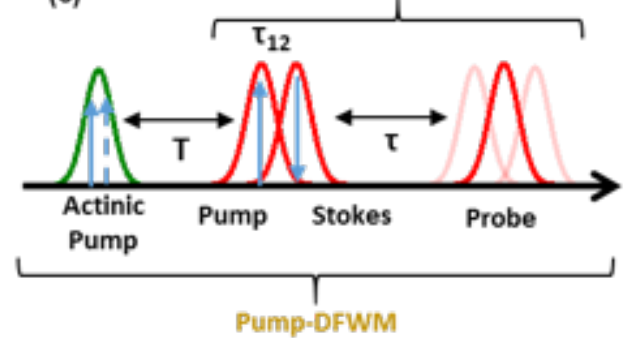

Figure 3: (a) Ground state absorption spectra of ASR in DA and LA condition. (b) Normalized difference absorption spectra at a pump-probe delay of $100 \mathrm{ps}$. Green and red (solid in (a) and line in (b)) curves represent the spectrum of AP and degenerate $P$. 
Impulsive vibrational spectroscopy (IVS) ${ }^{67,70-74}$, or femtosecond stimulated Raman (FSRS) ${ }^{75,76}$, allow to resolve such structural changes in the ground and electronically excited states up to the formation of photoproducts. A detailed study of the evolution and origin of vibrational modes in the ground and excited state has been done, for example, in the case of bacteriorhodopsin $(b R)^{53,64,74}$. Excitation of vibrational coherences in $b R$ has been shown to be highly dependent on the excitation wavelength in the spectral range from 520 up to $620 \mathrm{~nm}^{53}$. The "out-of-plane" modes of polyene-chain substituents and low frequency modes have been found to be very intense in the electronically excited state of $b R$. Contrasting to that, all remaining experimentally observed high frequency modes above $1010 \mathrm{~cm}^{-1}$ have to be assigned to the ground state manifold. A similar picture has been also observed for all-trans-retinal protonated Schiff-bases (RPSB). ${ }^{64}$ While the origin of the experimental vibrational spectra and the vibrational dynamics of other retinal based systems, like bR and RPSB, has been already established, very few is known for ASR. In particular, it is still unknown how the retinal isomerization and environment alters the topology of PES and hence vibrational dynamics. ${ }^{77}$ In this section, nonresonant DFWM and Pump-DFWM is applied to DA and LA ASR. In particular, all the high frequency modes $\left(>800 \mathrm{~cm}^{-1}\right)$ of ground states and photoproducts were compared both in DA and LA conditions.

Electronic Ground State of AT and 13C. Non-resonant DFWM transients detected at $610 \mathrm{~nm}$ in DA and LA conditions display strong high frequency oscillations (Figure 4 (a)-(b)). Respective FFT spectra show characteristic localized high frequency vibrational modes: DA ASR shows four main peaks at 1003 , 1165,1230 and $1530 \mathrm{~cm}^{-1}$; LA ASR shows only three major peaks at 1007,1180 and $1539 \mathrm{~cm}^{-1}$ and a smaller one at $1300 \mathrm{~cm}^{-1}$. The mode at about $1003 / 1007 \mathrm{~cm}^{-1}$ is assigned to the $\mathrm{CH}_{3}$ rocking, while the mode at $1530 / 1539 \mathrm{~cm}^{-1}$ is assigned to the $\mathrm{C}=\mathrm{C}$ stretching. ${ }^{53,64-66}$ The blue shift of the frequency of the $\mathrm{C}=\mathrm{C}$ stretching mode and the $\mathrm{CH}_{3}$-rocking mode (smaller shift) due to light adaptation agrees with previous experimental observation. ${ }^{74}$ The modes at 1165 and $1230 \mathrm{~cm}^{-1}$ observed for the DA ASR are characteristic for the $\mathrm{C}-\mathrm{C}$ single bond stretch of the AT retinal isomer. For $b R$, these two frequencies are at 1165

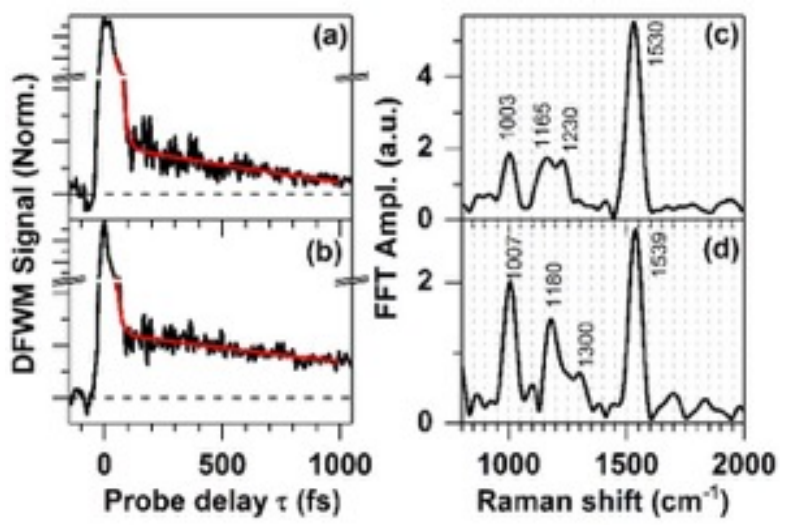

Figure 4:Non-resonant DFWM transients probed at 610nm: (a) DA ASR. (b) LA ASR. (c) FFT spectra of oscillatory signal of (a). (d) FFT spectra of oscillatory signal of (b). Non-oscillatory contribution (red line) was fitted by exponential decay and subtracted before FFT. $\mathrm{cm}^{-1}$ and $1210 \mathrm{~cm}^{-1}$. The respective C-C mode for the LA ASR is at $1180 \mathrm{~cm}^{-1} . \mathrm{In} \mathrm{bR}$, this mode is at $1190 \mathrm{~cm}^{-1}$ and is commonly attributed to the formation of the $13 \mathrm{C}$ isomer. ${ }^{78}$

The contributions of each isomer to the DA and LA signals can be separated by fitting the individual FFT spectra with Gaussian line shapes and considering the isomer content in each case. Since DA ASR contains almost pure-AT isomer, a fitting of the respective FFT spectra delivers the pure vibrational frequencies and widths of AT ground state modes. This information can be used to disentangle the pure-13C spectra by using a constrained double Gaussian fit for LA ASR, here orange-adapted, which contains both AT and $13 \mathrm{C}$ isomer. This is illustrated for the $\mathrm{C}=\mathrm{C}$ stretching mode (Figure 5(a)). In this case, the centre frequency and width of one Gaussian was fixed to the value obtained by single Gaussian fitting of DA ASR (=AT) (see Table S3 in ESI for fitting parameters). As the second Gaussian basically represents only the signature of $13 \mathrm{C}$, the pure contribution of $13 \mathrm{C}$ can be retrieved by using HPLC isomeric ratio $(58 \% 13 \mathrm{C}+42 \%$ AT, Table 1). A comparison of AT and reconstructed-13C spectra shows that the $\mathrm{C}=\mathrm{C}$ line shape is narrower and lower in amplitude. A similar approach can also be applied to the $\mathrm{CH}_{3}$ rocking mode to separate the AT and 13C-isomeric contributions (see $\mathrm{SI}$ ). The frequency difference of this mode for AT and $13 \mathrm{C}$ is about $5 \mathrm{~cm}^{1}$, while the widths are comparable within the fitting error. Separation of the isomeric contribution to the peaks in the fingerprint region $1100-1400 \mathrm{~cm}^{-1}$ is more challenging due to the strong spectral overlap between Raman lines and will be presented elsewhere.

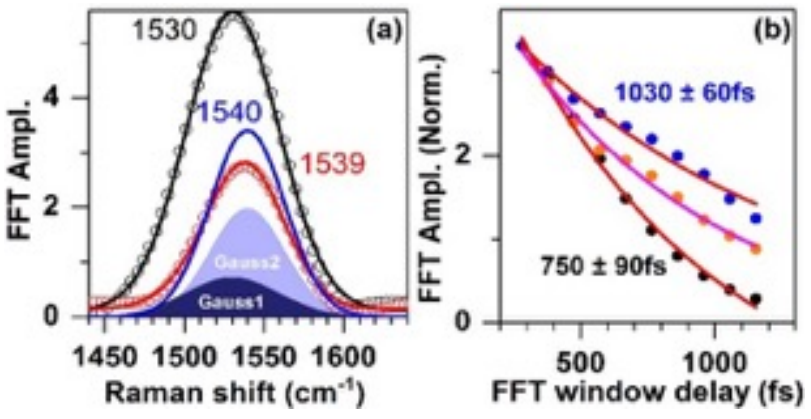

Figure 5: (a) Gaussian fit of C=C stretching mode of GS ASR in DA (black curve) and LA (red curve) conditions. The DA GS peak was fitted with a single Gaussian. For LA GS, a double Gaussian constrained fit was performed fixing the centre and width of first Gauss ian (Gauss1) as obtained by fitting the DA GS. The Gaussians required to fit the LA GS line shape are shown as filled curves. The reconstructed pure-13C spectrum is represented as blue line. (b) Exponential fit of dephasing of GS $C=C$ stretching mode obtained by sliding window FFT. Dephasing of DA (=AT), LA and extracted $13 \mathrm{C}$ isomer are shown by black, orange and blue dots. Red and pink solid line represents the exponential and constrained bi-exponential fitting, respectively.

The different Gaussian widths obtained for the $13 \mathrm{C}\left(52 \mathrm{~cm}^{-1}\right)$ and AT $\left(68 \mathrm{~cm}^{-1}\right)$ above suggests that the $\mathrm{C}=\mathrm{C}$ mode undergoes different dephasing dynamics for each isomer, i.e. the $C=C$ mode for the $13 \mathrm{C}$ isomer dephases much slower than for AT. This can be further corroborated by directly comparing the dephasing rates via a sliding window FFT along several probe delays $\tau^{53}$. Figure 5 (b) compares the decay of the amplitude of the $C=C$ mode obtained this way for the AT (=DA GS) and $13 C$ 
(retrieved from LA data). While the $\mathrm{C}=\mathrm{C}$ stretching dephases with a lifetime of about $750 \mathrm{fs}$ in the AT GS, the same mode in the ground state of the $13 \mathrm{C}$ GS dephases slower with a time constant of $1030 \mathrm{fs}$. Moreover, since the LA form contains both AT and 13C, a constrained bi-exponential fitting reproduces well

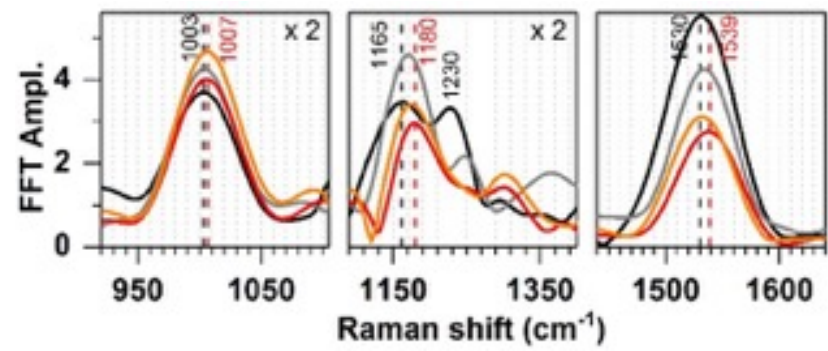

Figure 6: Comparison of FFT spectra of DA and LA ASR for different vibrational modes. Black and red curves show FFT spectra of ground state of ASR in DA and LA condition. Grey and orange curve represents the FFT spectra obtained from Pump-DFWM transient at $\mathrm{T}=100 \mathrm{ps}$ for DA and LA condition, respectively.

the LA spectra by fixing the time constants ( $750 \mathrm{fs}$ and $1030 \mathrm{fs}$ ) obtained for AT and 13C, but keeping the amplitudes free (Figure 5(b)).

K photoproducts - In order to compare the K photoproduct's vibrational signature with the electronic ground state of each isomer (see above), pump-DFWM experiment was carried out. $A$ resonant AP pulse was used to initiate the isomerization reaction. The DFWM pulse sequence, which was set spectrally resonant to the photoproduct absorption (Error! Reference source not found.), was delayed by $\mathrm{T}=100 \mathrm{ps}$. At this delay, the isomerization of $\mathrm{C}_{13}=\mathrm{C}_{14}$ is completed and a vibrationally relaxed K-photoproduct is already obtained ${ }^{60,61}$. The pump-DFWM signal measured shows similar vibrations as DFWM but with slightly shifted frequencies. FFT spectra of respective transients show for DA ASR four peaks at 1003, 1170, 1245 and $1535 \mathrm{~cm}^{-1}$ while for LA ASR peak frequencies are at 1007, 1174, 1305 and

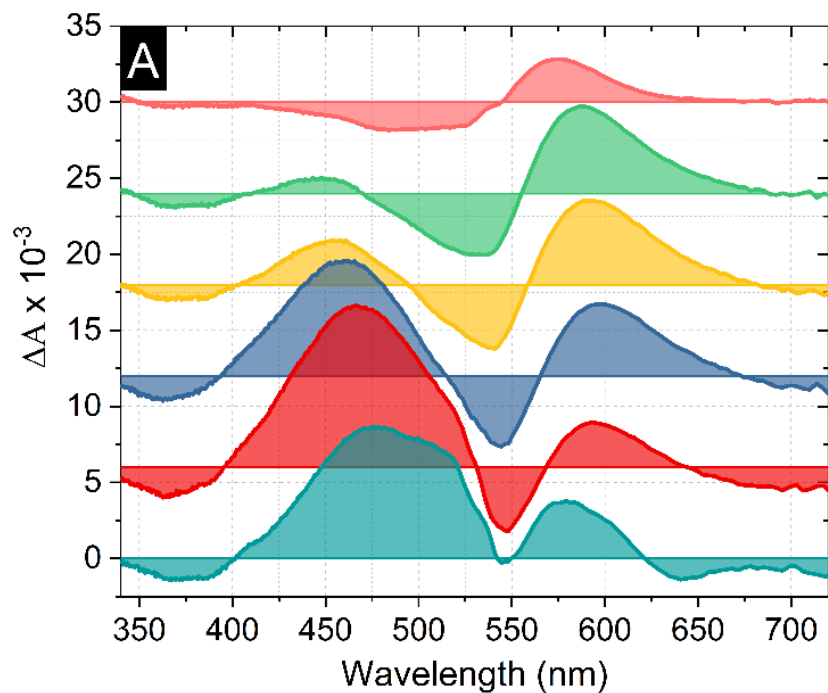

$1532 \mathrm{~cm}^{-1}$ (Figure 6). Table 2 in $\mathrm{SI}$ compares all values for the ground states of DA, LA and at T=100ps.

Discussion - Comparison of the FFT spectra obtained for the ground state of AT and $13 \mathrm{C}$ isomers and the respective photoproducts shows three major features regarding frequency shifts. The first one is the blue shift of the $\mathrm{C}=\mathrm{C}$ stretching band (1530 to $1535 \mathrm{~cm}^{-1}$ ) from GS to $T=100 \mathrm{ps}$ in DA condition, whereas it gets red shifted (1539 to $1532 \mathrm{~cm}^{-1}$ ) in LA conditions (Fig. 4 and Table S4 in ESI). These differences can be rationalized by the structural differences at the $C_{13}$ and $C_{15}$ double bonds for the ground states and the respective photoproducts. For the two isomers in the ground state, both double bonds are trans (AT) or cis (13C) isomerized, which results in a $10 \mathrm{~cm}^{-1}$ blue shift for this mode (Fig. 3(a)). For the photoproducts, $K_{A T}$ and $K_{13 C}$ one of the two double bonds is in trans- while the other is in cisconformation. In this situation one expects a frequency for this mode between the $1530 \mathrm{~cm}^{-1}$ (AT) and $1540 \mathrm{~m}^{-1}$ (13C). Moreover, since at $\mathrm{T}=100 \mathrm{ps}$ the signal contains contributions of ground states as well as from the respective photoproducts, the frequency of $\mathrm{C}=\mathrm{C}$ stretching appears at a frequency between the frequency of the AT and $13 C$, i.e., at $1535 \mathrm{~cm}^{-1}$ in DA and $1532 \mathrm{~cm}^{-1}$ in LA condition. The second aspect is the absence of any shift for the $\mathrm{CH}_{3}$-rocking mode when the ground state is compared to the respective photoproduct (Table S4 in ESI). For example, for DA ground state as well as at $\mathrm{T}=100 \mathrm{ps}$ the frequency is $1003 \mathrm{~cm}^{-1}$. This contrasts with the frequency shift observed for the ground states of AT $\left(1003 \mathrm{~cm}^{-1}\right)$ and $13 \mathrm{C}$ $\left(1007 \mathrm{~cm}^{-1}\right)$, and suggests that the $\mathrm{CH}_{3}$ rocking mode is more sensitive when isomerization at both $\mathrm{C}_{13^{-}}$and $\mathrm{C}_{15}$-positions takes place. The last and more complex aspect of the frequency shifts observed is in the fingerprint region between 1100 and $1400 \mathrm{~cm}^{-1}$. Although many vibrational modes are overlapping in this region, large changes in frequency from GS to $T=100 \mathrm{ps}$ are quite evident. Similar to $C=C$ stretching mode, the $1165 \mathrm{~cm}^{-1}$ mode blue shifts to $1170 \mathrm{~cm}^{-1}$ for DA ASR whereas in LA condition, $1180 \mathrm{~cm}^{-1}$ red shifts to $1174 \mathrm{~cm}^{-1}$. In addition, a band at $1230 \mathrm{~cm}^{-1}$ observed for DA GS is reduced at $\mathrm{T}=100 \mathrm{ps}$. This

Figure 7: Time-resolved TAS spectra for the AT forms of W76F (A) and L83Q (B) for highlighting delays up to 1.0 ps and a long-time, 90 ps, GS-K difference spectrum. Note the prominant spectral shifts of ESA, GSB and SE in the first $200 \mathrm{fs}$. 
band vanishes for LA ASR whereas a new peak around $1300 \mathrm{~cm}^{1}$ appears. It is very similar to the $13 \mathrm{C}$ isomer of $\mathrm{bR}^{79,80}$ and Channelrhodopsin ${ }^{73}$, where it has been assigned to $\mathrm{CH}_{3}$ rocking and marked as signature of cis-configuration.

\section{Effects of point mutations on the photo-reaction kinetics of all- trans,15-anti PSBR}

The reaction kinetics of the all-trans species are retrieved from TAS data measured on DA mutants, as described in Materials and Methods. Figure 7 reports the time-resolved TAS spectra for $\mathrm{W} 76 \mathrm{~F}$ and $\mathrm{L} 83 \mathrm{Q}$, at time delays between $40 \mathrm{fs}$ and $1.0 \mathrm{ps}$, and long-time difference spectra (90 ps) representing the AT- $\mathrm{K}_{\mathrm{AT}}$ difference spectra.

Until 100-150 fs, the spectra show a prominent excited state absorption (ESA) in the range from 420 to $620 \mathrm{~nm}$, and stimulated emission (SE), beyond $630 \mathrm{~nm}$. During this early time period, significant dynamic spectral shifts are observed redistributing the ESA spectral intensity to shorter wavelengths, and allowing for the ground state bleach (GSB) to show up progressively as a trough in the ESA (L83Q-AT) or a negative signal (W76F-AT). This is most obvious for L83Q-AT, where the ESA max. shifts from 550 to $540 \mathrm{~nm}$ within $60 \mathrm{fs}$. This initial phase of relaxation $(<0.1 \mathrm{ps})$ is attributed to exc. state relaxation, most likely due to $\mathrm{C}=\mathrm{C}$ bond length alternation and IVR. GSB is observed at all delay times at wavelengths shorter than $400 \mathrm{~nm}$.

After $100 \mathrm{fs}$, the ESA and SE globally decay in amplitude, indicating excited state decay due to isomerization. In contrast, the spectral range between 570 and $670 \mathrm{~nm}$, displays now an increasing diff. absorption, consistent with the formation of the $\mathrm{J}_{\mathrm{AT}}$ photo-product, as reported for wt-ASR ${ }^{44,47}$. The high-energy part of ESA, 400-500 $\mathrm{nm}$, continues decaying and slightly blueshifting until $1.0 \mathrm{ps}$. It is not clear, whether the remaining amplitude at $430-450 \mathrm{~nm}$ is ESA or part of the GS-J ${ }_{\text {AT }}$ difference spectrum, slowly decaying on a ps timescale (see below).

The spectral overlap of ESA and $\mathrm{J}_{\mathrm{AT}}$, throughout the entire 420$620 \mathrm{~nm}$ range, requires a careful analysis of the TAS transients for the determination of the excited state lifetime (ESL) and isomerisation reaction time (IRT). The SE decay reflects the ESL on a zero background and is therefore of particular relevance (see below). In addition, ESL and IRT have to be consistent with the PP rise time.

For L83Q, the ESA decay in the blue part of the spectrum after the initial $100-\mathrm{fs}$ spectral shift can be fitted at $445 \mathrm{~nm}$ with a biexponential decay, featuring a dominant $120 \pm 10$ fs component and a 10 -times smaller $0.76 \pm 0.13$ ps component (Figure $8 \mathrm{a}$ ). For shorter wavelengths, where the $\mathrm{J}$ absorption is negligible (424 $\mathrm{nm}$, not shown) the slower component vanishes. The SE decay at $>700 \mathrm{~nm}$ is purely mono-exponential with a $110 \pm 10 \mathrm{fs}$ decay (see ESI, fig. S5) indicating clearly that the $S_{1}$ population decays on this ultrafast timescale, i.e. 7 times faster than AT in wt$\mathrm{ASR}^{47}$. This corroborated by the $110 \pm 10 \mathrm{fs}$ risetime of the $J_{A T} P P$ absorption followed by a $1.54 \pm 0.06$ ps decay due to $J_{A T} \rightarrow K_{A T}$ relaxation (Figure $8 \mathrm{c}$ ). The GSB in the $507 \mathrm{~nm}$ trace sets in only after the initial ESA decay and cannot inform about the isomerization-related GS recovery (Figure $8 \mathrm{~b}$ ). Nevertheless,
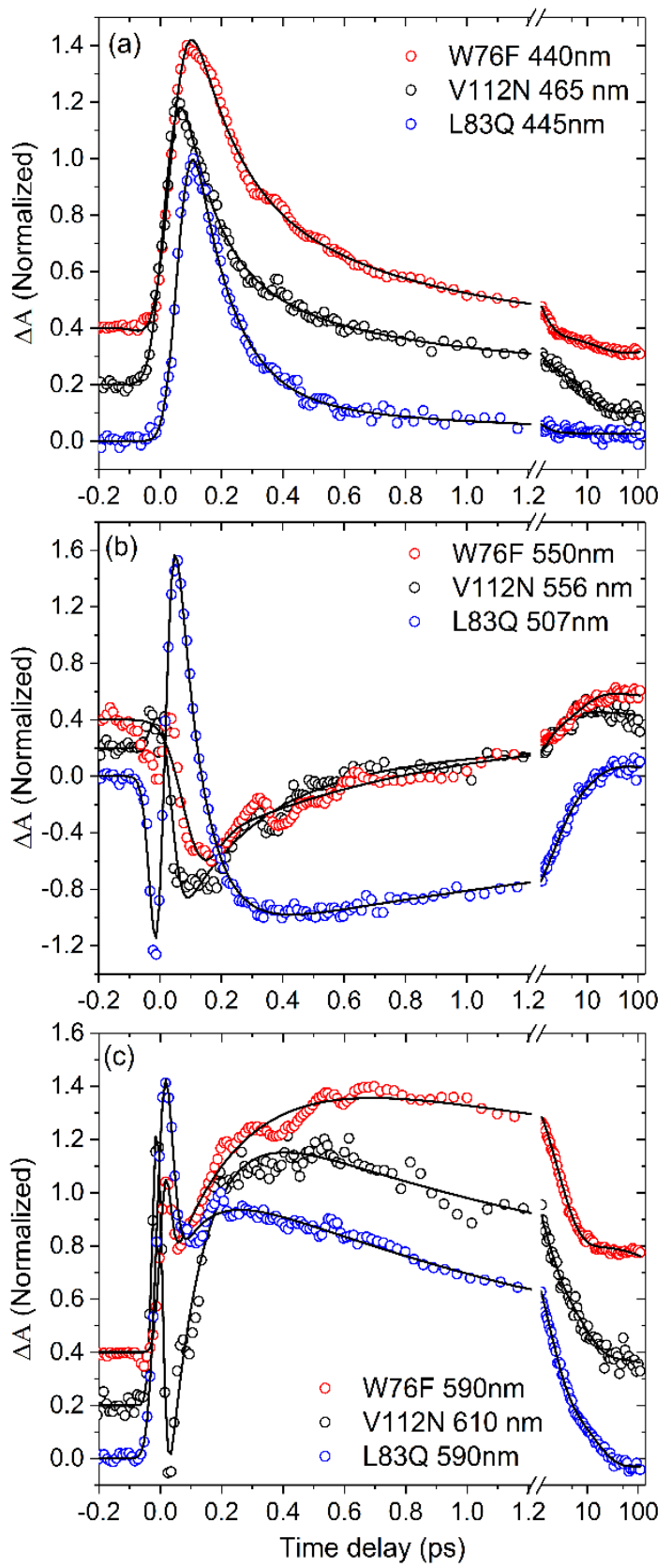

Figure 8: Normalized kinetic traces of the AT isomer in the 3 mutants, and probed at the wavelengths indicated. (a) ESA decay, (b) GSB recovery, (c) PP formation. Solid lines represent fits, according to the parameters discussed in the text. The W76F and $\mathrm{V} 112 \mathrm{~N}$ traces are displaced vertically.

from the ESA, SE and PP kinetics it is clear that the IRT for L83QAT is $110 \pm 10 f s$.

For W76F, the ESA decay at $440 \mathrm{~nm}$ shows a bi-exponential decay with a dominant $140 \pm 10$ fs component and a 2.0-times smaller $0.70 \pm 0.03$ ps component (Figure 8a). The slower component is present also in ESA traces at shorter wavelengths where the $J$ contribution is smaller (e.g. $415 \mathrm{~nm}$, not shown) even with a smaller amplitude. The SE at $>700 \mathrm{~nm}$ does not afford a high SNR (see ESI, fig. S5), but a mono-exponential fit yields an excited state lifetime of $360 \pm 20 \mathrm{fs}$, in good agreement with a weighted average of the above ESA components. We thus conclude that for W76F the S1 decay is biphasic. In the PA 
trace at $590 \mathrm{~nm}$ (Figure 8c), only a fast $240 \pm 20$ fs rise component is observed, followed by a slower 2.55 ps $\mathrm{J}_{A T} \rightarrow \mathrm{K}_{\mathrm{AT}}$ relaxation decay. The GSB recovery displays significant nonexponential features (Figure $8 \mathrm{~b}$ ), but the non-oscillating part is consistent with the above biphasic isomerization reaction (Table 3).

The situation is not as clear for V112N. Here, the ESA decay is bi-exponential with a dominant $110 \pm 10 \mathrm{fs}$ and a 2.6-times smaller $490 \pm 80 \mathrm{fs}$. SE is weaker at $>700 \mathrm{~nm}$ than for the other mutants (see ESI, fig. S5), and shows a dominant $110 \pm 10$ fs component. The existence of a slower decay component cannot be excluded but is hidden in the noise floor. The PP rise is clearly faster than for $V 112 \mathrm{~N}$ and shows only the fastest $110 \pm 10 \mathrm{fs}$ rise component followed by a slower 1.1 ps decay due to $\mathrm{J}_{A T} \rightarrow \mathrm{K}_{\mathrm{AT}}$ relaxation decay (Figure $8 \mathrm{~b}$ ). The GSB recovery, at $556 \mathrm{~nm}$, also displaying oscillatory features as the PP kinetics, can be best fitted by a fast $250 \pm 30$ fs component, indicating that the isomerization is not completed on a $110 \mathrm{fs}$ timescale, but that the IRT is made most likely composed of the above two 110 and $490 \mathrm{fs}$ components. A weighted average gives $210 \mathrm{fs}$. We retain $230 \pm 20$ fs for the IRT (see Table 3).

In summary, we find IRT's from 110 to 340 fs for the three mutants, which is 2 to 7 times shorter than the one for wt-ASR. We note that the blue-shift of the ground state absorption of AT correlates with a shorter IRT, with respect to wt-ASR. Notably, a similar correlation, though with less amplitude in the IRTs, was predicted theoretically by comparing different RPs ${ }^{81}$.

\section{Effects of point mutations on the photo-reaction kinetics of 13- cis,15-syn PSBR}

The 13C-specific TAS kinetics are extracted from the LA data following the decomposition procedure used in ref. ${ }^{47}$. Here we take into account the ground state isomer composition determined by HPLC under exactly the same LA conditions, and the excited state isomer composition calculated from the pump laser spectrum and the relative absorption amplitudes of AT and $13 \mathrm{C}$ (figure 1).

The effects of the mutations on the ESL and IRT are evaluated from selected ESA, GSB and PP kinetics. SE kinetics are not available with high enough signal-to-noise ratio for the $13 \mathrm{C}$ isomers. The time-resolved spectra are qualitatively equivalent to the ones observed for AT (Figure 7), and will not be shown here. Figure 9 displays the relevant kinetics for the 3 mutants. The longest ESL is observed for V112N (240 $\pm 30 \mathrm{fs})$ in the ESA, which displays an additional 5.7 ps decay time, 12 times smaller in amplitude, most probably due to a longer-lived signal assigned to the $\mathrm{J}_{13 \mathrm{C}}$ intermediate. The PP rise and GSB recovery times are 310 and $340 \mathrm{fs}$, respectively. Taken together, the IRT is $290 \pm 50 \mathrm{fs}$ for this mutant, i.e. twice as long as for wt-ASR. For $L 83 Q$, the IRT of $13 \mathrm{C}$ is slightly longer than in wt-13C. We find $200 \pm 40 \mathrm{fs}$, as a combination of ESA decay (220 fs), PP rise (160 fs) and GSB recovery (220fs). ESA shows an additional 8times smaller $4.3 \mathrm{ps}$ decay component, which is attributed again to the $\mathrm{J}_{13 \mathrm{C}}$ intermediate. The $13 \mathrm{C}$ reaction kinetics in $\mathrm{W} 76 \mathrm{~F}$ do not seem to be affected by the mutations, since it is found to be $120 \pm 30 \mathrm{fs}$, as a result of ESA decay $(120 \pm 30 \mathrm{fs}$, 8 times larger
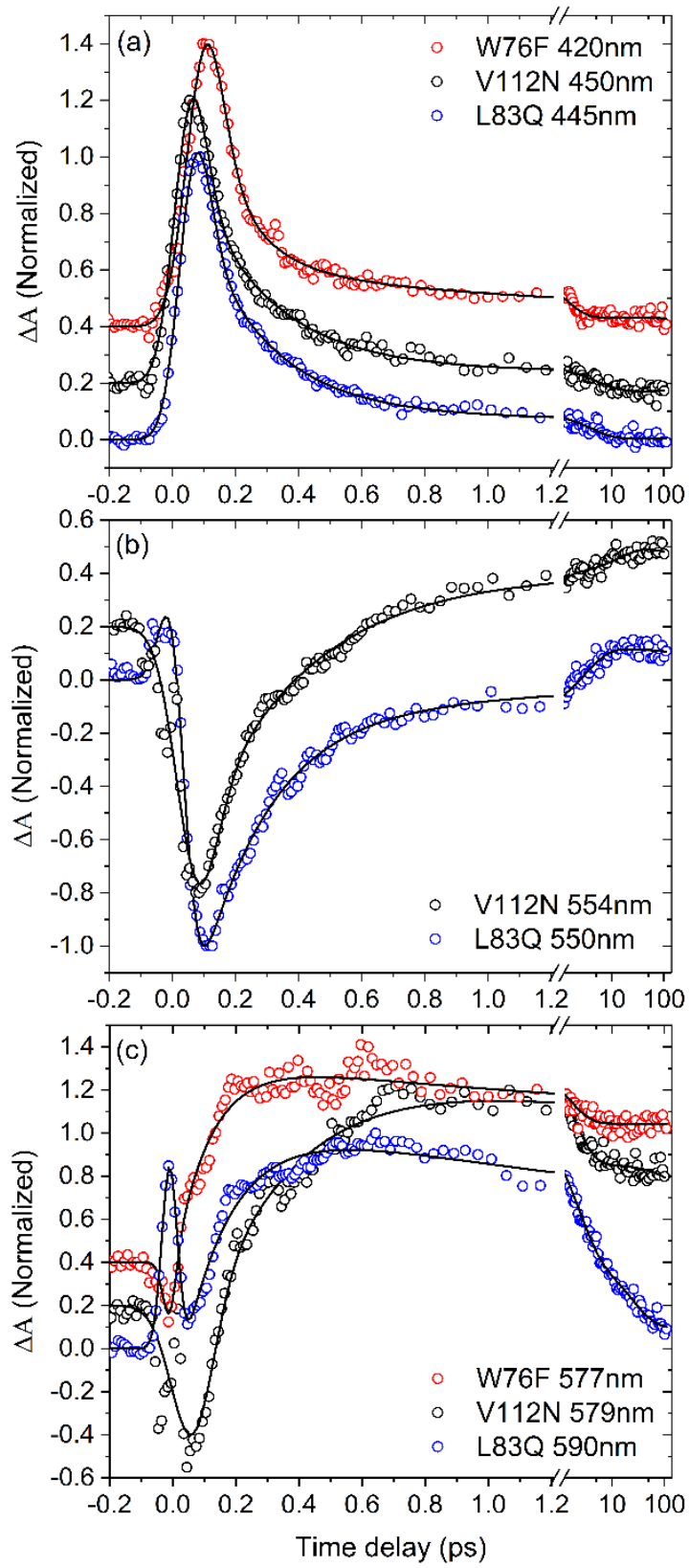

Figure 9: Normalized kinetic traces of the $13 \mathrm{C}$ isomer in the 3 mutants, and probed at the wavelengths indicated. (a) ESA decay, (b) GSB recovery, (c) PP formation. Solid lines represent fits, according to the parameters discussed in the text. The W76F and V112N traces are displaced vertically.

amplitude than a spurious 1.5 ps component) and PP rise (110 $\pm 10 \mathrm{fs})$.

Interestingly, mutations with hydrophilic groups tend to slow down the IRT of the $13 \mathrm{C}$ isomer, while it significantly accelerates isomerization for the ATs (Table 3). For L83Q, the IRT of $13 \mathrm{C}$ is now slower than for AT, while the former is 7 times shorter than the latter in wt-ASR. Nevertheless, disregarding wt-ASR, the same trend as for AT is observed: a larger blue-shift of the absorption spectrum leads to a shorter IRT (Figure 10).

Since the strongest effect of an enhanced IRT is observed for V112N, with a mutation in the vicinity of the ionone ring, i.e. far away from the $\mathrm{C} 12=\mathrm{C} 13$ double bond, the mechanism is most 
likely due to an electrostatic rather than a steric effect. Detailed excited state trajectory computations are needed, but the experimental results suggest that the 13C-PSBR excited state dipole moment increases during the reaction in a manner that reduces the slope of the $S_{1}$ PES, so as to slow down the excited state decay, with respect to the situation in wt-13C.

\begin{tabular}{|c|c|c|c|c|c|c|}
\hline Sample & Isomer & $A_{1}$ & $\tau_{1}(\mathrm{fs})$ & $A_{2}$ & $\tau_{2}(f s)$ & IRT (fs) \\
\hline \multirow[t]{2}{*}{ W76F } & AT & 0.67 & $140 \pm 10$ & 0.33 & $700 \pm 30$ & $340 \pm 40$ \\
\hline & $13 C$ & 1.0 & $120 \pm 30$ & & & $120 \pm 30$ \\
\hline \multirow[t]{2}{*}{ V112N } & AT & 0.72 & $110 \pm 10$ & 0.28 & $490 \pm 80$ & $230 \pm 20$ \\
\hline & $13 C$ & 1.0 & $290 \pm 50$ & & & $290 \pm 50$ \\
\hline \multirow[t]{2}{*}{ L83Q } & AT & 1.0 & $120 \pm 30$ & & & $120 \pm 30$ \\
\hline & $13 C$ & 1.0 & $200 \pm 40$ & & & $200 \pm 40$ \\
\hline
\end{tabular}

Table 3: Isomerization reaction times for AT and 13 isomers in the 3 mutants studied. Times are determined from ESA decay, PP rise and GSB recovery times. A2 $\neq 0$ refers to bi-phasic exc. state population decay. See text for details.

\section{Conclusions and outlook}

This paper reports the first detailed study on two aspects of the spectroscopy of Anabaena Sensory Rhodopsin, namely the vibrational spectra of the primary photo-products $K_{A T}$ and $K_{13 C}$ of wt-ASR and the effects of point mutations of ASR on the excited state decay and isomerization reaction times of the mutants V112N, W76F and L83Q. The ground state absorption spectra of these mutants are all blue-shifted with respect to wtASR and our quantum chemistry computations show that the electrostatic interactions in the PSBR binding pocket are responsible for the colour tuning in $\mathrm{V} 112 \mathrm{~N}$ and $\mathrm{W} 76 \mathrm{~F}$. The transient absorption experiments show quite dramatic shortenings of the $S_{1}$ lifetimes and IRT's of the AT isomer with respect to wt-ASR. To the best of our knowledge, a 7-fold reduction of the excited state lifetime, as observed here for L83Q-AT is unique for a retinal protein, for which mutations generally induce slower and less efficient isomerization reactions. Such a slow-down is observed for the $13 \mathrm{C}$. It is interesting to note that for AT, the shorter IRT's go along with the blue-shifted absorption spectra. Our strategy to proceed both experimentally and theoretically for providing a detailed comprehensive understanding of the mutation effects and of PSBR-protein interactions in general has made first progress, but it hinges presently on obtaining an adequate model for $\mathrm{L} 83 \mathrm{Q}$, and for realistic excited state trajectories for the three mutants. The time-resolved vibrational spectra will provide additional experimental data, to be tested by the $\mathrm{QM} / \mathrm{MM}$ simulations.

The vibrational spectra of $13 \mathrm{C}$ and AT of wt-ASR, as well as the respective photoproducts, show all features well-known for $b R$ and other rhodopsin systems in the region between 1000$1600 \mathrm{~cm}^{-1}$. In particular, the separation of the $13 \mathrm{C}$ and AT contributions was demonstrated for the $\mathrm{C}=\mathrm{C}$ and $\mathrm{C}-\mathrm{C}$ stretching modes. The dephasing of the $\mathrm{C}=\mathrm{C}$ for $13 \mathrm{C}$ is slower than for $\mathrm{AT}$ (1030 vs 750fs), hinting at a weaker coupling of this mode with the environment on the electronically ground state in respect to AT. Moreover, the frequency shifts detected and assigned for each isomer clearly show the potential of pump-DFWM to separate and resolve the small spectral changes due to mutation of ASR in the future.

Last, the specific biologic function of ASR, as a photo-receptor for light-intensity level, requires differences in the absorption spectra of AT and CIS and differences in their isomerization quantum yield, so as to allow for sizeable changes of the isomer content upon light- or dark-adaptation. It will therefore be extremely important in the future to determine experimentally and understand theoretically the effect of the mutations on the reaction quantum yield.

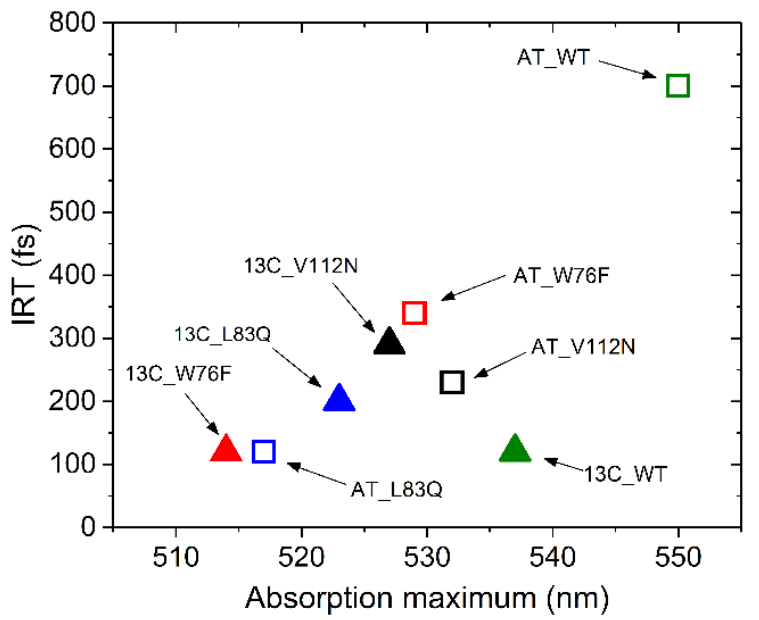

Figure 10: Isomerization reaction times with respect to absorption maxima of AT (open squares) and $13 \mathrm{C}$ isomers (triangles) in wt-ASR and three mutants.

\section{Conflicts of interest}

There are no conflicts to declare.

\section{Acknowledgements}

The Strasbourg team is grateful to Dr. A. Cheminal for his contribution to the initial phase of the experiments, and to Dr. O. Crégut, and J.-P. Vola and for technical assistance. The work was supported by the French-German ANR-DFG grant FemtoASR (ANR- 14-CE35-0015-01) and by the Labex NIE (ANR-11LABX-0058_NIE). The France-Korea collaboration is supported by CNRS in the framework of the "LIA NanoFunc". M.O. is grateful for a USIAS 2015 Fellowship, and funding through the NSF Grant No. CHEM 1710191. D. A. thanks the "region Alsace" for partial funding of his PhD contract. 


\section{Notes and references}

1. H. J. Polland, M. A. Franz, W. Zinth, W. Kaiser, E. Kölling and D. Oesterhelt, Biophysical Journal, 1986, 49, 651-662.

2. J. W. Petrich, J. Breton, J. L. Martin and A. Antonetti, Chem. Phys. Lett, 1987, 137, 369-375.

3. J. Herbst, K. Heyne and R. Diller, Science, 2002, 297, 822-825.

4. R. Diller, in Biological and Medical Physics, Biomedical Engineerin, eds. M. Braun, P. Gilch and W. Zinth, Springer, Berlin Heidelberg, 2008, pp. 243-273.

5. J. Briand, J. Leonard and S. Haacke, J Optics-Uk, 2010, 12.

6. A. Wand, I. Gdor, J. Y. Zhu, M. Sheves and S. Ruhman, Annu. Rev. Phys. Chem., 2013, 64, 437-458.

7. I. Schapiro and S. Ruhman, Biochimica et Biophysica Acta (BBA) Bioenergetics, 2014, 1837, 589-597.

8. S. Ruhman, B. X. Hou, N. Friedman, M. Ottolenghi and M. Sheves, Journal of the American Chemical Society, 2002, 124, 8854-8858.

9. G. I. Groma, A. Colonna, J. C. Lambry, J. W. Petrich, G. Váró, M. Joffre, M. H. Vos and J.-L. Martin, Proc. Nat. Acad. Sci., 2004, 101, 7971-7975.

10. S. Schenkl, F. van Mourik, G. van der Zwan, S. Haacke and M Chergui, Science, 2005, 309, 917-920.

11. P. Kukura, D. W. McCamant, S. Yoon, D. B. Wandschneider and R. A. Mathies, Science, 2005, 310, 1006-1009.

12. D. W. McCamant, P. Kukura and R. A. Mathies, Journal of Physical Chemistry B, 2005, 109, 10449-10457.

13. J. P. Kraack, T. Buckup, N. Hampp and M. Motzkus, Chemphyschem, 2011, 12, 1851-1859.

14. J. P. Kraack, T. Buckup and M. Motzkus, Physical Chemistry Chemical Physics, 2012, 14, 13979-13988.

15. V. I. Prokhorenko, A. M. Nagy, S. A. Waschuk, L. S. Brown, R. R. Birge and R. J. D. Miller, Science, 2006, 313, 1257-1261.

16. G. Vogt, P. Nuernberger, T. Brixner and G. Gerber, Chemical Physics Letters, 2006, 433, 211-215.

17. P. J. M. Johnson, A. Halpin, T. Morizumi, V. I. Prokhorenko, O. P. Ernst and R. J. Dwayne Miller, EPJ Web of Conferences, 2013, 41, 07020.

18. D. Polli, P. Altoe, O. Weingart, K. M. Spillane, C. Manzoni, D. Brida, G. Tomasello, G. Orlandi, P. Kukura, R. A. Mathies, M. Garavelli and G. Cerullo, Nature, 2010, 467, 440-U488.

19. T. Sovdat, G. Bassolino, M. Liebel, C. Schnedermann, S. P. Fletcher and P. Kukura, Journal of the American Chemical Society, 2012, 134, 8318-8320.

20. L. M. Frutos, T. Andruniow, F. Santoro, N. Ferre and M. Olivucci, Proc Natl Acad Sci U S A, 2007, 104, 7764-7769.

21. T. Andruniów, N. Ferré and M. Olivucci, Proc. Nat. Acad. Sci. USA, 2004, 101, 17908-17913.

22. M. Ben-Nun, F. Molnar, K. Schulten and T. J. Martínez, Proceedings of the National Academy of Sciences, 2002, 99, 17691773.

23. F. Molnar, M. Ben-Nun, T. J. Martínez and K. Schulten, J. Mol. Struct., 2000, 506, 169-178.

24. A. Cembran, F. Bernardi, M. Olivucci and M. Garavelli, Proc. Nat. Acad. Sci. USA, 2005, 102, 6255-6260.

25. I. Schapiro, M. N. Ryazantsev, L. M. Frutos, N. Ferre, R. Lindh and M. Olivucci, Journal of the American Chemical Society, 2011, 133, 3354-3364.

26. I. Rivalta, A. Nenov, O. Weingart, G. Cerullo, M. Garavelli and S. Mukamel, J Phys Chem B, 2014, 118, 8396-8405.

27. P. Hamm, M. Zurek, T. Röschinger, H. Patzelt, D. Oesterhelt and W. Zinth, Chem. Phys. Lett, 1996, 263, 613-621.
28. S. L. Logunov, M. A. ElSayed, L. Song and J. K. Lanyi, J Phys ChemUs, 1996, 100, 2391-2398.

29. O. Bismuth, N. Friedman, M. Sheves and S. Ruhman, The journal of physical chemistry. B, 2007, 111, 2327-2334.

30. O. Bismuth, N. Friedman, M. Sheves and S. Ruhman, Chem Phys, 2007, 341, 267-275.

31. G. Zgrablić, S. Haacke and M. Chergui, Chem. Phys., 2007, 338 168.

32. G. Zgrablic, S. Haacke and M. Chergui, Journal of Physical Chemistry B, 2009, 113, 4384-4393.

33. G. Zgrablic, K. Voitchovsky, M. Kindermann, S. Haacke and M. Chergui, Biophysical Journal, 2005, 88, 2779-2788.

34. G. Bassolino, T. Sovdat, M. Liebel, C. Schnedermann, B. Odell, T. D. W. Claridge, P. Kukura and S. P. Fletcher, Journal of the American Chemical Society, 2014, 136, 2650-2658.

35. T. Ye, N. Friedman, Y. Gat, G. H. Atkinson, M. Sheves, M. Ottolenghi and S. Ruhman, Journal of Physical Chemistry, 1999, 103, 5122.

36. S. Haacke, S. Schenkl, S. Vinzani and M. Chergui, Biopolymers, 2002, 67, 306-309.

37. S. Haacke, S. Vinzani, S. Schenkl and M. Chergui, ChemPhysChem, 2001, 2, 310-315.

38. G. Zgrablic, S. Haacke and M. Chergui, J Phys Chem B, 2009, 113, 4384-4393.

39. G. Zgrablić, A. M. Novello and F. Parmigiani, J. Am. Chem. Soc., 2011, 134, 955-961.

40. I. Burghardt and J. T. Hynes, The Journal of Physical Chemistry $A$, 2006, 110, 11411-11423.

41. L. Vogeley, O. A. Sineshchekov, V. D. Trivedi, J. Sasaki, J. L. Spudich and H. Luecke, Science, 2004, 306, 1390-1393.

42. A. Kawanabe, Y. Furutani, K.-H. Jung and H. Kandori, Journal of the American Chemical Society, 2007, 129, 8644-8649.

43. A. Strambi, B. Durbeej, N. Ferré and M. Olivucci, Proceedings of the National Academy of Sciences, 2010, 107, 21322-21326.

44. A. Wand, R. Rozin, T. Eliash, K.-H. Jung, M. Sheves and S. Ruhman, Journal of the American Chemical Society, 2011, 133, 20922-20932.

45. R. Rozin, A. Wand, K. H. Jung, S. Ruhman and M. Sheves, The journal of physical chemistry. B, 2014, 118, 8995-9006.

46. A. Wand, B. Loevsky, N. Friedman, M. Sheves and S. Ruhman, Journal of Physical Chemistry B, 2013, 117, 4670-4679.

47. A. Cheminal, J. Leonard, S.-Y. Kim, K.-H. Jung, H. Kandori and S. Haacke, Physical Chemistry Chemical Physics, 2015, 17, 25429-25439. 48. A. Cheminal, J. Leonard, S. Y. Kim, K. H. Jung, H. Kandori and S. Haacke, Chemical Physics Letters, 2013, 587, 75-80.

49. R. M. Weiss and A. W. Warshel, J. Am. Chem. Soc., 1979, 101, 6131-6133.

50. Y. Wada, A. Kawanabe, Y. Furutani, H. Kandori and H. Ohtani, Chemical Physics Letters, 2008, 453, 105-108.

51. J. Briand, O. Braem, J. Rehault, J. Leonard, A. Cannizzo, M Chergui, V. Zanirato, M. Olivucci, J. Helbing and S. Haacke, Physical Chemistry Chemical Physics, 2010, 12, 3178-3187.

52. J. Hauer, T. Buckup and M. Motzkus, Journal of Physical Chemistry A, 2007, 111, 10517-10529.

53. J. P. Kraack, T. Buckup, N. Hampp and M. Motzkus*, Chemical Physcical Chemistry, 2011, 12, 1851-1859.

54. T. Buckup and M. Motzkus, Annual review of Physical Chemistry, 2015, 65, 39-57.

55. F. Melaccio, M. Del Carmen Marin, A. Valentini, F. Montisci, S. Rinaldi, M. Cherubini, X. Yang, Y. Kato, M. Stenrup, Y. OrozcoGonzalez, N. Ferre, H. L. Luk, H. Kandori and M. Olivucci, J Chem Theory Comput, 2016, 12, 6020-6034. 
56. A. Zen, E. Coccia, S. Gozem, M. Olivucci and L. Guidoni, J Chem Theory Comput, 2015, 11, 992-1005.

57. L. Andersen, I. Nielsen, M. Kristensen, M. El Ghazaly, S. Haacke, M. Nielsen and M. Petersen, Journal of the American Chemical Society, 2005, 127, 12347-12350.

58. R. A. Mathies, C. H. B. Cruz, W. T. Polard and C. V. Shank, Science, 1988, 240, 777-779.

59. Q. Wang, R. W. Schoenlein, L. A. Peteanu, R. A. Mathies and C. V. Shank, Science, 1994, 266, 422-424.

60. A. Kawanabe, Y. Furutani, K.-H. Jung and H. Kandori, Journal of American Chemical Scociety, 2007, 129, 8644-8649.

61. A. Kawanabe and H. Kandori, Sensors, 2009, 9, 9741-9804.

62. O. A. Smitienko, M. N. Mozgovaya, I. V. Shelaev, F. E. Gostev, T. B. Feldman, V. A. Nadtochenko, O. M. Sarkisov and M. A. Ostrovsky, Biochemistry, 2009, 75, 34-45.

63. A. V. Sharkov, A. V. Pakulev, S. V. Chekalin and a. Y. A. Matveetz, Biochimica et Biophysica Acta, 1985, 808, 94-102.

64. J. P. Kraack, T. Buckup and M. Motzkus, Physical Chemistry Chemical Physics, 2011, 13, 21402-21410.

65. J. P. Kraack, T. Buckup and M. Motzkus, Physical Chemistry Chemical Physics, 2012, 14, 13979-13988.

66. J. P. Kraack, T. Buckup and M. Motzkus, Journal of Physical Chemistry Letter, 2013, 4, 383-387.

67. J. P. Kraack, A. Wand, T. Buckup, M. Motzkus and S. Ruhman, Physical Chemistry Chemical Physics, 2013, 15, 14487--14501.

68. M. S. Marek, T. Buckup and M. Motzkus, Journal of Physical Chemistry B, 2011, 115, 8328-8337.

69. T. Miki, T. Buckup, M. S. Krause, J. Southall, R. J. Cogdell and M. Motzkus, Physical Chemistry Chemical Physics, 2016, 18, 11443-11453.

70. S. Fujiyoshi, S. Takeuchi and T. Tahara, Journal of Physical Chemistry A, 2003, 107, 494-500.

71. M. Liebel and P. Kukura, Journal of Physical Chemistry Letter, 2013, 4, 1358-1364.

72. M. Liebel, C. Schnedermann and P. Kukura, Physical Review Letters, 2014, 112, 198302.

73. C. Schnedermann, V. Muders, D. Ehrenberg, R. Schlesinger, P. Kukura and J. Heberle, Journal of American Chemical Scociety, 2016, 138, 4757-4762.

74. A. Kahan, O. Nahmias, N. Friedman, M. Sheves and S. Ruhman, Journal of American Chemical Scociety, 2007, 129, 537-546.

75. P. Kukura, D. W. McCamant, S. Yoon, D. B. Wandschneider and R. A. Mathies, Science, 2005, 310, 1006-1009.

76. P. Kukura, D. W. McCamant and R. A. Mathies, Annual review of Physical Chemistry, 2007, 58, 461-488.

77. I. Schapiro, J Phys Chem A, 2016, 120, 3353-3365.

78. S. Shim, J. Dasgupta and R. A. Mathies, Journal of the American Chemical Society, 2009, 131, 7592-7597.

79. M. Braiman and R. Mathies, Proceedings of the National Academy of Sciences, 79, 403-407.

80. S. Smith, J. A. Pardoen, J. Lugtenburg and R. A. Mathies, Journal of Physical Chemstry, 1987, 91, 804-819.

81. S. Rinaldi, F. Melaccio, S. Gozem, F. Fanelli and M. Olivucci, Proc Natl Acad Sci U S A, 2014, 111, 1714-1719.

82. Y.Orozco-Gonzalez, M. Manathunga, M. del Carmen Marín, D. Agathangelou, K.-H. Jung, F. Melaccio, N. Ferré, S. Haacke, K. Coutinho, S. Canuto, M. Olivucci, J Chem Theory Comput, 2017 (in press). 